\title{
The Distribution of Light Nonmethane Hydrocarbons over the Mid-Atlantic: Results of the Polarstern Cruise ANT VII/1
}

\author{
R. KOPPMANN, R. BAUER, F. J. JOHNEN, C. PLASS, and J. RUDOLPH
}

\begin{abstract}
During the cruise ANT VII/1 (September/October 1988) of the German research vessel Polarstern the latitudinal distributions of several nonmethane hydrocarbons were measured over the Atlantic between $45^{\circ} \mathrm{N}$ and $30^{\circ} \mathrm{S}$ by in-situ gas chromatography.

On the average, the highest mixing ratios of ethane, propane, $i$ - and $n$-butane, ethene and acetylene were observed in the Northern Hemisphere around $40^{\circ} \mathrm{N}$ and just north of the intertropical convergence zone, respectively. South of the equator, a bulge in the mixing ratios of ethane and acetylene was observed indicating aged biomass burning emissions. This observation coincided with enhanced tropospheric ozone found in this region at this season. On the average ethane and acetylene mixing ratios were around 500 and $100 \mathrm{ppt}$, respectively, whereas the levels of the other NMHC were in the range of some ppt up to $100 \mathrm{ppt}$.

Compared with the results of the cruise ANT V/5 (March/April, 1987), the ethane mixing ratios in September/October proved to be a factor of 3 lower in the Northern Hemisphere and a factor of 2 higher in the Southern Hemisphere, probably due to seasonal effects. Possible causes are the higher $\mathrm{OH}$ radical concentrations in summer, which result in a faster removal of ethane or stronger emission from biomass burning which also peaks in the dry season.

The relative pattern of the hydrocarbons just north of the ITCZ was very similar for both measurement series. In this region, the NMHC were advected by long-range transport from the continent, whereas generally the ocean itself acts as a major NMHC source. This is supported by the results of a balance calculation between oceanic emissions and atmospheric removal rates.
\end{abstract}

Key words: Hydrocarbons, carbon monoxide, marine atmosphere, Atlantic, hydrocarbon budgets

\section{Introduction}

The photochemical oxidation of CO, methane, and light NMHC in the atmosphere affects the production and destruction of ozone depending on the concentration of NO. Furthermore, NMHC may determine up to $30 \%$ of the concentration of the $\mathrm{OH}$ radical in the remote marine troposphere (Liu et al., 1989; Donahue and Prinn, 1990). While the large-scale distributions of $\mathrm{CO}$ and $\mathrm{CH}_{4}$ are reasonably well known (cf. Schmidt et al., 1982), most of the NMHC show a considerable variability in their tropospheric mixing ratios (Rudolph and Ehhalt, 1981; Rasmussen and Khalil, 1982; Singh and Salas, 1982; Rudolph et al., 1982; Rudolph et al., 1984; Bonsang and Lambert, 1985; Greenberg and Zimmermann, 1984; 
Ehhalt et al., 1985; Rudolph, 1988; Rudolph and Johnen, 1990). The mixing ratios of the longer-lived compounds exhibit a number of systematic variations, whereas the distribution of the shorter-lived species show a considerable variability in these measurement series. In general, the NMHC mixing ratios in the remote troposphere are well below $1 \mathrm{ppb}$. Results of recent measurement series (cf. Rudolph and Johnen, 1990, and references therein) confirm that many light NMHC have substantial oceanic sources. Measurements in the surface water of the ocean show that light NMHC are supersaturated relative to the atmosphere (e.g. Bonsang et al., 1988; Plass et al., 1992). In this paper, we provide measurements conducted over the mid-Atlantic between $45^{\circ} \mathrm{N}$ and $30^{\circ} \mathrm{S}$ and estimate the contribution of the oceanic NMHC source based on emission rates calculated from measurements in surface water and reported in Plass et al. (1992).

\section{Experiment}

The light NMHC were measured by in-situ gas chromatography. The instrument was installed in a container on the port side of the navigation deck about $20 \mathrm{~m}$ above sea level. The air intake line extended about $4 \mathrm{~m}$ beyond the hull of the ship in order to avoid contamination by ship emissions. In cases where relative wind direction and velocity indicated possible contamination from the ship, the measurements have been rejected (details of the sampling location, wind directions, etc., are given by Platt et al. (1992)). The stainless steel line (10 mm ID) was permanently flushed with outside air at a flow rate of $30 \mathrm{dm}^{3} \mathrm{~min}^{-1}$ to minimize wall losses and contaminations.

The samples were preconcentrated at liquid nitrogen temperature on a precolumn packed with porous glass beads from 1.5 to $3.5 \mathrm{dm}^{3}$ (STP) of air. The samples were injected into a gas chromatograph, where the light fraction $\left(\mathrm{C}_{2}-\mathrm{C}_{4}\right)$ was separated on a packed column (6 m, $2 \mathrm{~mm}$ ID, Porapack OS, 100/120 mesh) and the heavy fraction $\left(\mathrm{C}_{5}-\mathrm{C}_{10}\right)$ on a fused silica column (DB5, $60 \mathrm{~m}, 0.32 \mathrm{~mm}$ ID). The hydrocarbons were measured by a flame ionization detector (FID). The technique is very similar to the one described by Rudolph et al. (1986). The analog signal of the FID was digitized and acquired by a personal computer using commercial chromatography software. The data were stored on tape for later processing.

The atmospheric mixing ratios were calculated by comparing the sample with a reference air of known composition. The mixing ratios of the different hydrocarbons in the reference air were in the range of a fraction of a ppb to a few ppt, comparable with the levels in ambient air. The reproducibility of the measurements was about $10 \%$ for the $\mathrm{C}_{2}$ hydrocarbons and $30 \%$ for the $\mathrm{C}_{3}$ and $\mathrm{C}_{4}$ hydrocarbons. These reproducabilities were determined from several measurements of reference air samples made during the whole cruise. Therefore, it includes all factors which effect the sensitivity of the system over a period of about one month. The lower limit of detection was 5-10 ppt. The lower limit of detection was given by the base- 
line noise of the FID, which was increased by the motion of the ship due to the change of the flame position relative to the collector electrode. In order to reduce this noise, a second FID was operated at the same conditions using carrier gas only. Ship motion induced the same noise signals in this FID as in the primary detector. Subtraction of the signals substantially reduced the noise level induced by the motion of the ship. The time required for one measurement including the preconcentration step was $3 \mathrm{~h}$. The instrument allowed automatic, unattended operation for $24 \mathrm{~h}$ a day. With the exception of periods for testing, calibration and maintenance of the instrument measurements were made continuously.

Carbonmonoxide was measured with a commercial reduction gas analyser (RGA 3, Trace Analytical Inc.). One measurement was made every 15 min. Additionally, whole air grab samples were taken two times a day, which were later analysed for $\mathrm{CO}$. However, relative to the in-situ measurements the $\mathrm{CO}$ measurements from the grab samples showed nearly a factor of 2 higher concentrations, which is not yet understood, but probably due to calibration problems. Therefore, we can only discuss a relative latitudinal $\mathrm{CO}$ distribution.

The cruise started on 15 September 1988 at Bremerhaven, West Germany and ended on 9 October 1988 at Rio Grande do Sul, Brazil. Between $30^{\circ} \mathrm{N}$ and $30^{\circ} \mathrm{S}$ the cruise track followed $30^{\circ}$ western longitude (cf. Platt et al., 1992). The measurements cover the period from 18 September $1988\left(45^{\circ} \mathrm{N}\right)$ to 5 October 1988 $\left(30^{\circ} \mathrm{S}\right)$.

\section{Results}

Ninety-two measurements of light NMHC were made during this cruise of $R V$ Polarstern (ANT VII/1), 4 of which had to be rejected due to suspected contamination by the ship's exhaust (see above). For the other measurements the relative wind speed and direction showed that the sampled air was free from any possible influence of ship emissions. The measured mixing ratios of ethane, propane, $i$ butane, $n$-butane, ethene and acetylene are plotted in Figures $1 \mathrm{a}-\mathrm{f}$ as a function of latitude. All measurements of the $\mathrm{C}_{2}$-hydrocarbons gave values well above the detection limit with a reproducibility of about $10 \%$. Analysis of the $\mathrm{C}_{3}$-hydrocarbons proved to be difficult due to an interference with the water peak in the chromatograms. Propene was still detectable in $40 \%$ of the chromatograms, but in most cases an additional interference with an unknown peak was observed. Consequently, in these cases propene could not be evaluated quantitatively, and is therefore not included in the further discussion. Propane was detectable in $45 \%$ of the chromatograms with a reproducibility of about $30 \%$. Due to technical problems the first measurements of butane started at $40^{\circ} \mathrm{N}$. Only for about $50 \%$ of the measurements the $i$ - and $n$-butane concentrations were above the detection limit. 


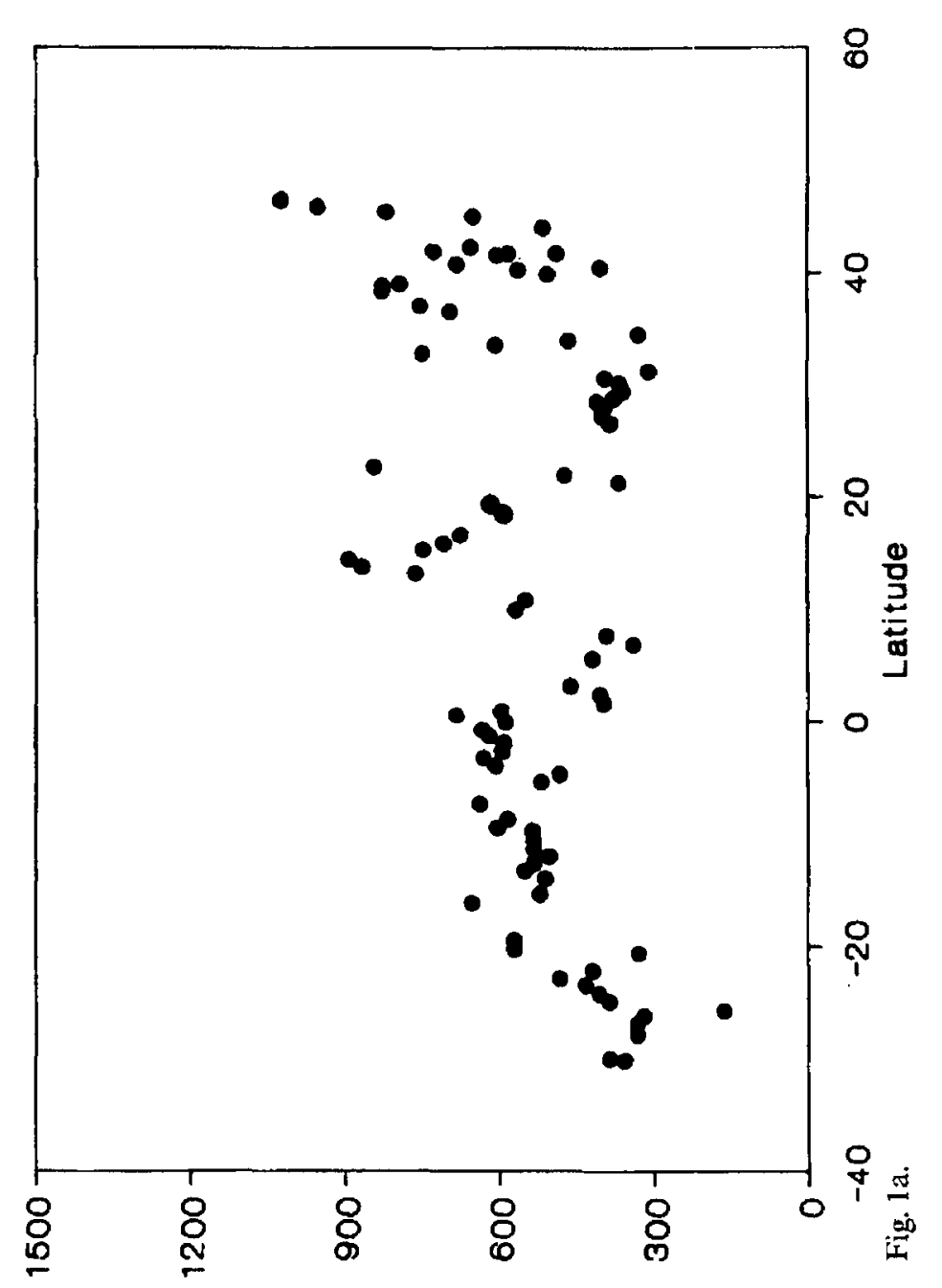

ldd / aubuţ

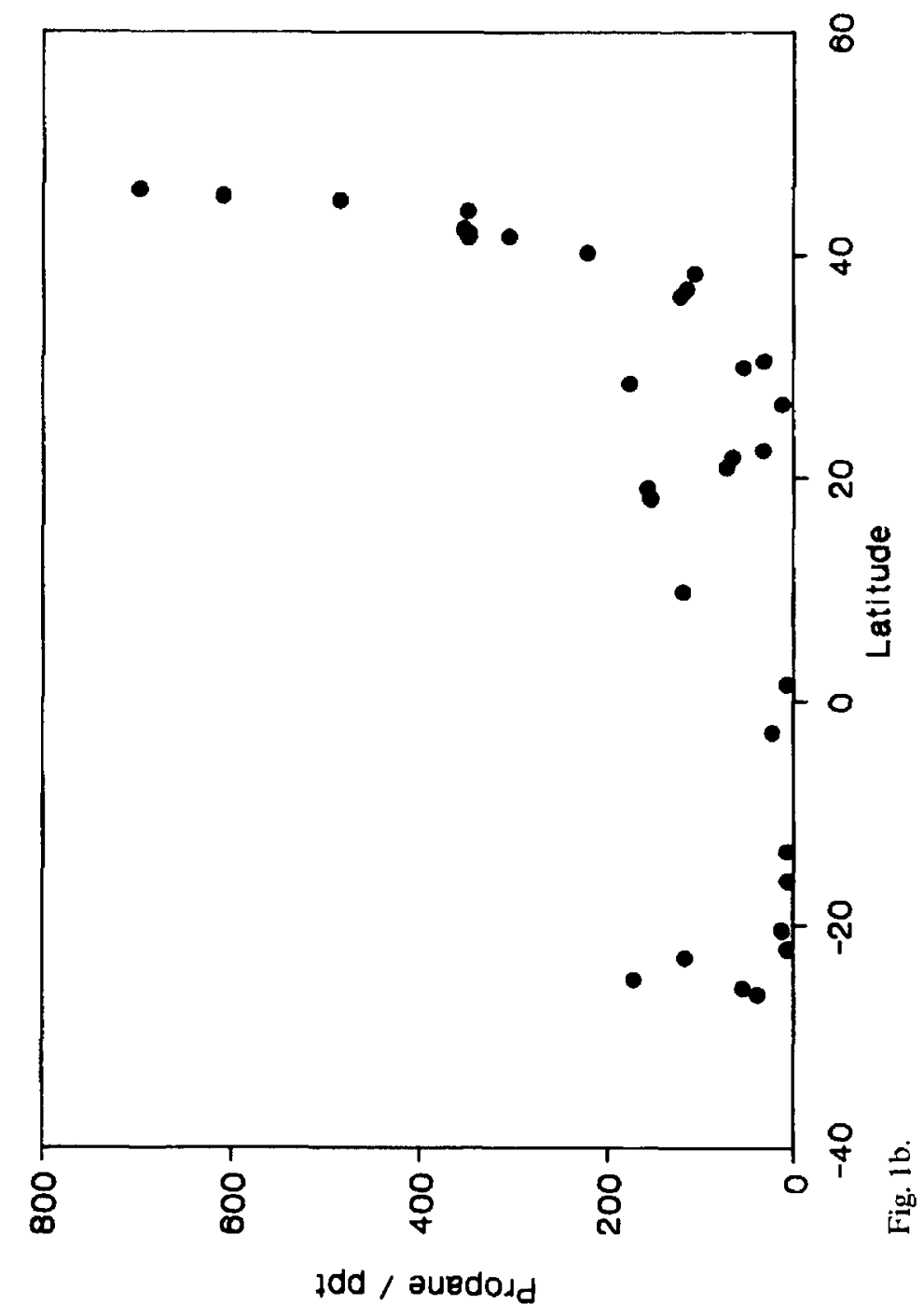

Idd / aurdodd 

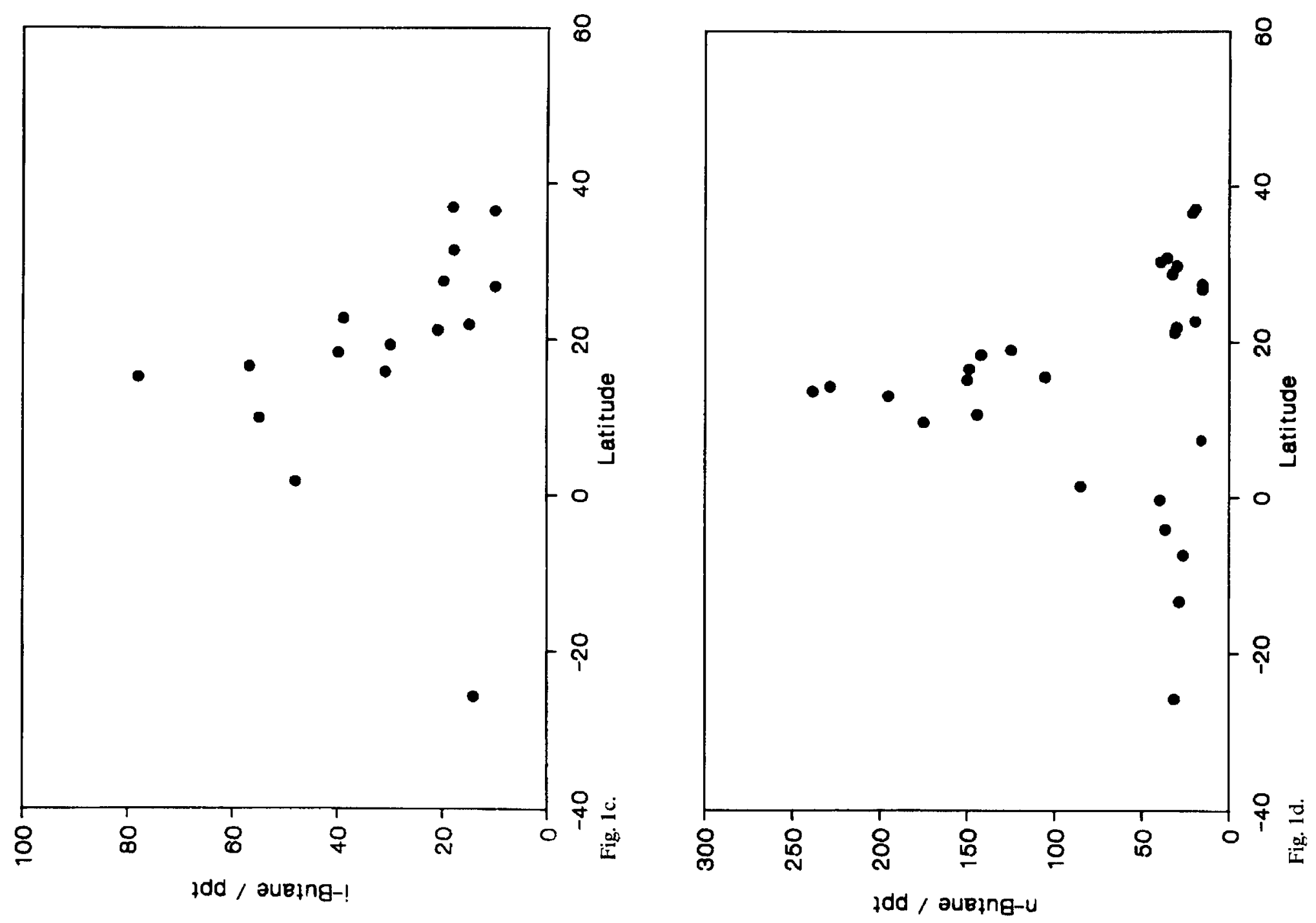

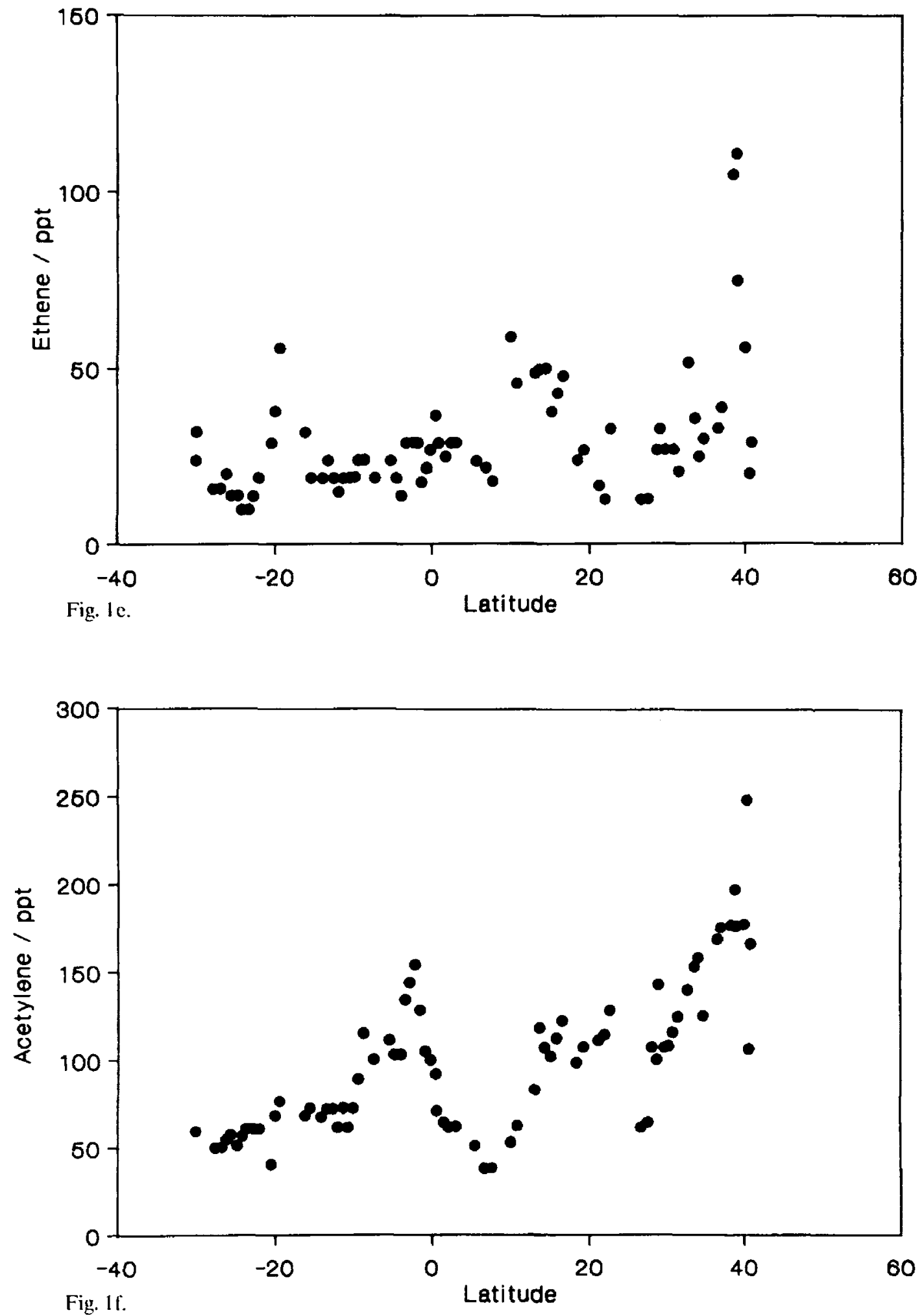

Fig. 1. Plot of hydrocarbon mixing ratios as a function of latitude, $(+)=$ Northern Hemisphere, $(-)=$ Southern Hemisphere. (a) ethane, (b) propane, (c) $i$-butane, (d) $n$-butane, (c) ethene, (f) acetylene. 


\section{Discussion}

\subsection{The Latitudinal Distribution of Ethane}

The by far most abundant NMHC in the remote marine troposphere is ethane. It showed no significant interhemispheric difference in this measurement series. Average mixing ratios were $605 \pm 189 \mathrm{ppt}$ in the Northern Hemisphere and $500 \pm 117 \mathrm{ppt}$ in the Southern Hemisphere. However, there are a number of major structures in the latitudinal ethane distribution which are primarily caused by transport. Between $35^{\circ} \mathrm{N}$ and $20^{\circ} \mathrm{N}$ ethane showed relatively low mixing ratios. These are obviously due to the meteorological situation. The air masses were advected by a stable high pressure region over the Atlantic. Four-day backward trajectories on the $850 \mathrm{hPa}$ level indicated that the air masses had no contact with continents for several days (Figure 2) (K. Arpe, private communication). Between $20^{\circ} \mathrm{N}$ and the intertropical convergence zone (ITCZ) the situation changed. The backward trajectories indicated a recent contact of the air masses with the African continent (Figure 2).

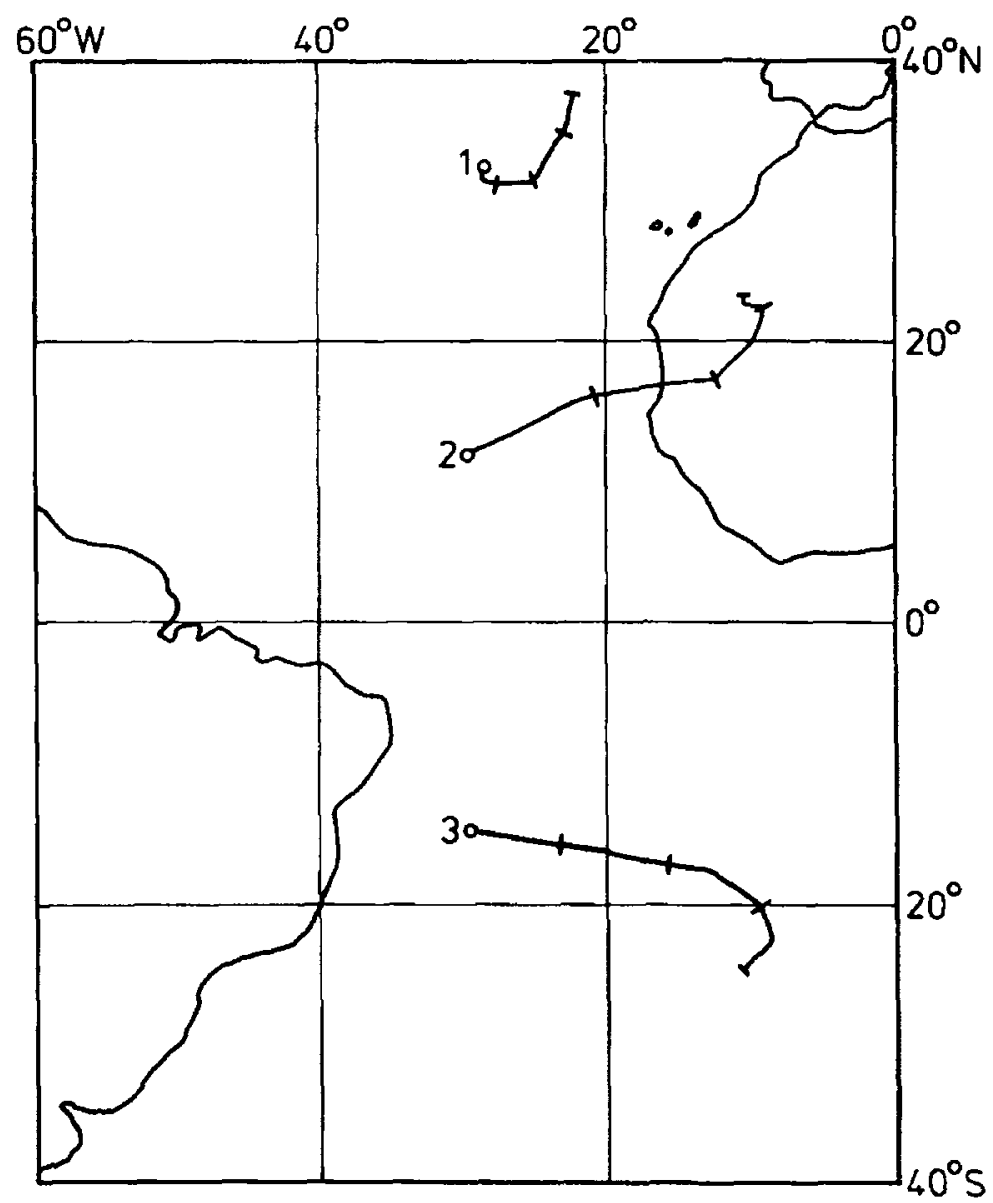

Fig. 2. Four day backward trajectories on the $850 \mathrm{hPa}$ level, the circles mark the position of the ship on 1:23 September 1988;2:27 September 1988, 3:2 October 1988. 
In this region $\left(20^{\circ} \mathrm{N}-8^{\circ} \mathrm{N}\right)$ the mixing ratios increased again. A maximum was observed just north of the ITCZ of about $900 \mathrm{ppt}$. In the ITCZ ethane levels decreased by a factor of 3 but increased again just south of the equator. This increase is most probably due to the impact of emissions from biomass burning on the sampled air masses. Similar increases can also be seen for other tracers of biomass burning such as acetylene (see Figure 1f), $\mathrm{CO}$ and some other trace gases. As a consequence of the photochemical oxidation of these tracers elevated $\mathrm{O}_{3}$ mixing ratios were measured (Smit et al., 1990). These results also agree with the data published by Fishman et al. (1990), who reported tropospheric ozone distributions determined from satellite data between 1979 and 1987. For the period September to November, they found an area of significantly elevated $\mathrm{O}_{3}$ mixing ratios over the mid-Atlantic between $5^{\circ} \mathrm{S}$ and $25^{\circ} \mathrm{S}$.

With increasing southern latitudes ethane showed a quite steady decrease to about $350 \mathrm{ppt}$ at $30^{\circ} \mathrm{S}$. There are a number of measurement series of ethane in the marine background atmosphere, from over the Atlantic and over the Pacific (Bonsang and Lambert, 1985; Blake and Rowland, 1986; Ehhalt et al., 1985; Rasmussen and Khalil, 1982; Rudolph and Ehhalt, 1981; Rudolph et al., 1982; Rudolph et al., 1884; Rudolph and Johnen, 1990; Singh and Salas, 1982). However, in order to compare the different latitudinal distributions, we have to consider the existence of substantial seasonal cycles of ethane both in the Northern and in the Southern Hemispheres (Blake and Rowland, 1986; Rudolph et al., 1989). For the Pacific, Blake and Rowland (1986) published latitudinal distributions of ethane for September 1984 and March 1985. In the September measurements, ethane mixing ratios were below $1 \mathrm{ppb}$ in the Northern Hemisphere and around $400 \mathrm{ppt}$ in the Southern Hemisphere. On the other hand, for March, they report ethane mixing ratios up to $2.5 \mathrm{ppb}$ in the Northern and less than $200 \mathrm{ppt}$ in the Southern Hemispheres. This agrees with our Atlantic data for March/April 1987 (Rudolph and Johnen, 1990) and September/October 1988 (Table I).

Table I. Mixing ratios (ppt) of light NMHC in the marine atmosphere

\begin{tabular}{|c|c|c|c|c|}
\hline & \multicolumn{2}{|c|}{ Northern Hemisphere } & \multicolumn{2}{|c|}{ Southern Hemisphere } \\
\hline & $\begin{array}{l}\text { ANT V/5 } \\
\text { Mar./Apr. } \\
1987\end{array}$ & $\begin{array}{l}\text { ANT VIl/1 } \\
\text { Sept./Oct. } \\
1988\end{array}$ & $\begin{array}{l}\text { ANT V/5 } \\
\text { Mar./Apr. } \\
1987\end{array}$ & $\begin{array}{l}\text { ANT VII/1 } \\
\text { Sept./Oct. } \\
1988\end{array}$ \\
\hline Ethane & $1810 \pm 460$ & $605 \pm 189$ & $278 \pm 104$ & $500 \pm 117$ \\
\hline Propane & $360 \pm 220$ & $228 \pm 187$ & $11 \pm 26$ & $50 \pm 57$ \\
\hline$i$-Butane & $53 \pm 43$ & $27 \pm 21$ & $10 \pm 3$ & (1) \\
\hline$n$-Butane & $94 \pm 80$ & $85 \pm 77$ & $20 \pm 9$ & (1) \\
\hline Ethene & $58 \pm 26$ & $45 \pm 35$ & $25 \pm 18$ & $22 \pm 9$ \\
\hline Acetylene & - & $123 \pm 43$ & - & $81 \pm 29$ \\
\hline
\end{tabular}

(1) Most of the measurements were below detection limit. 
Another data set showing the seasonal variation of ethane in the Southern Hemisphere is published by Rudolph et al. (1989). These data collected over a period of 4 years at the Georg-von-Neumeyer station, Antarctica, clearly show the existence of a seasonal cycle with highest mixing ratios occurring in September and lowest mixing ratios between January and March. Also, the absolute values correspond very well to the values given by Blake and Rowland (1986) and our measurements: $450 \mathrm{ppt}$ in September and $300 \mathrm{ppt}$ in March. Due to the mean atmospheric lifetime, ethane seems to be reasonably well mixed in the remote troposphere. Therefore, our average mixing ratios seem to be representative for the Southern Hemisphere at this season.

\subsection{The Distributions of Ethene, Propane, and Acetylene}

The latitudinal structures shown by most of the other NMHC are in some aspects similar to the distribution of ethane, but also significant differences can be seen. Ethene and propane showed regions of highest mixing ratios around $45^{\circ} \mathrm{N}$ (about 100 and $700 \mathrm{ppt}$, respectively) and also somewhat elevated levels just north of the ITCZ (about $50 \mathrm{ppt}$ and $150 \mathrm{ppt}$, respectively). Low mixing ratios of only some 10 ppt were observed for both compounds between $20^{\circ} \mathrm{N}$ and $30^{\circ} \mathrm{N}$ and in the ITCZ. However, they exhibited no increase south of the equator and for both compounds a substantial interhemisphere difference could be seen (cf. Table I). Also the relative gradients are much steeper than for ethane.

The $i$ - and $n$-butane data set is too limited to allow a detailed discussion, but the range of increased mixing ratios directly north of the ITCZ is rather pronounced for both compounds.

The distribution of acetylene differed in many aspects from those of the other NMHC, but it still showed some of the features visible in the ethane profiles. The highest acetylene values of about $200 \mathrm{ppt}$ were found around $40^{\circ} \mathrm{N}$ and there was a minimum of about $30 \mathrm{ppt}$ in the ITCZ. But there is little evidence for a minimum between $20^{\circ} \mathrm{N}$ and $30^{\circ} \mathrm{N}$ and a maximum directly north of the ITCZ. The pronounced increase directly south of the equator is also visible for acetylene, but differs in shape from ethane. The range of elevated mixing ratios is primarily restricted to a narrow latitude band of less than $10^{\circ}$ and from $10^{\circ} \mathrm{S}$ towards higher latitudes the decrease is only rather small.

The acetylene mixing ratios and latitudinal gradients are both comparable with the data published by Robinson (1978) who found $\mathrm{C}_{2} \mathrm{H}_{2}$ mixing ratios in the Northern Hemisphere between $300 \mathrm{ppt}$ at $50^{\circ} \mathrm{N}$ and $50 \mathrm{ppt}$ at the equator. The decrease with latitude found in our measurements is a factor of 2 lower than the gradient reported by Rudolph and Ehhalt (1981) for January/February 1979 and by Rudolph et al. (1984) for February/March 1983. Furthermore, on the average the absolute mixing ratios differ by a factor of 2 , which probably indicates a seasonal variation in the Northern Hemisphere. Jones (1988) reports a seasonal cycle of acetylene at Harwell, Great Britain, with mixing ratios in January/February being a 


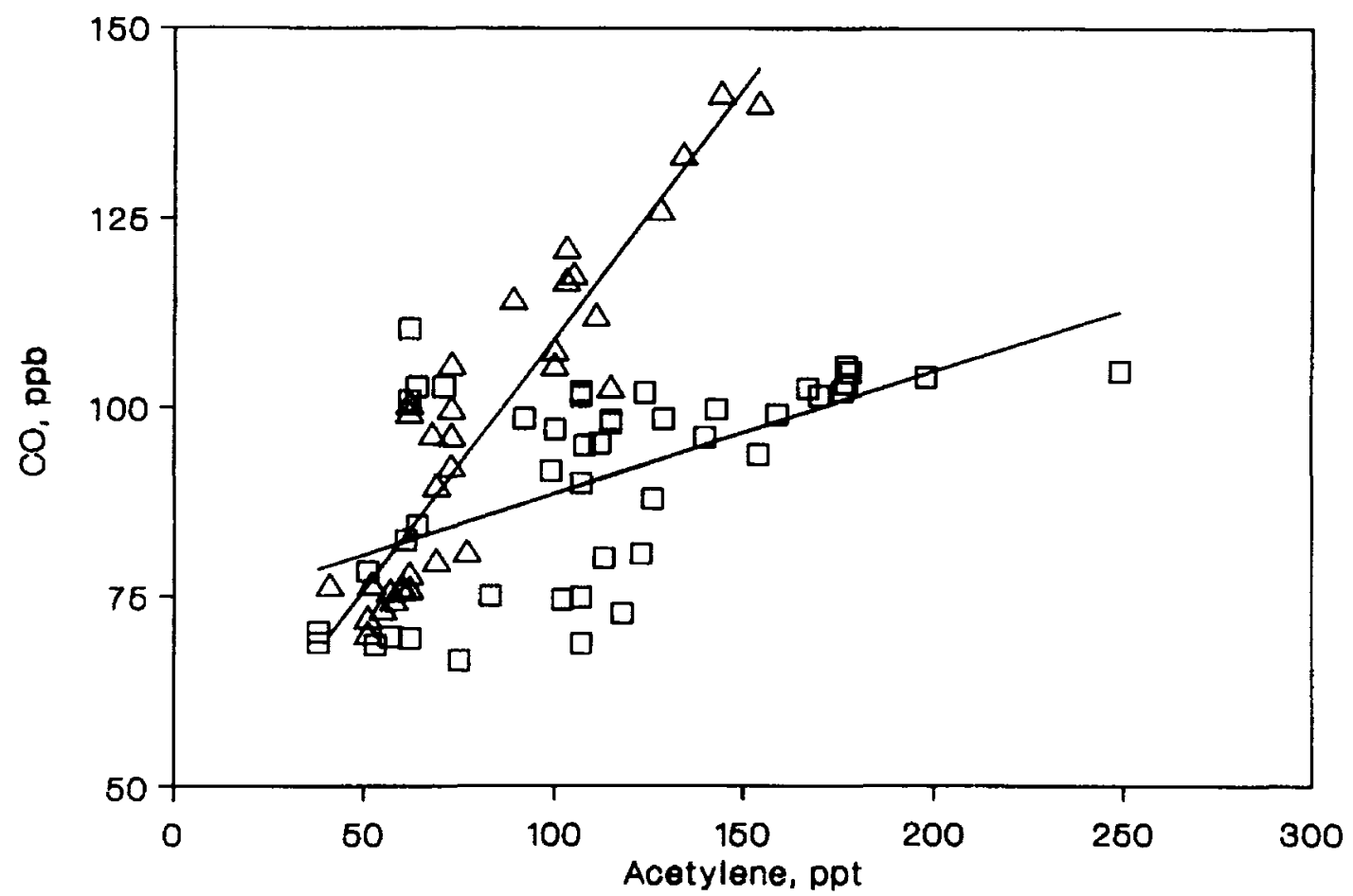

Fig. 3. Plot of $\mathrm{CO}$ mixing ratios versus $\mathrm{C}_{2} \mathrm{H}_{2}$ mixing ratios. $\square$ : Northern Hemisphere, $\Delta$ : Southern Hemisphere.

factor of 3 higher than in September/October. Measurements of acetylene in Antarctica showed a seasonal cycle in the Southern Hemisphere with highest mixing ratios occurring between August and October (Rudolph et al., 1989).

Similar latitudinal patterns can be seen for $\mathrm{CO}$. Figure 3 shows a plot of $\mathrm{CO}$ versus $\mathrm{C}_{2} \mathrm{H}_{2}$. In this plot different symbols are used for the measurements in the Northern and Southern Hemispheres. The CO data used here are the results from the in-situ measurements since this is the most complete data set. Calculation of a linear regression yields

$$
[\mathrm{CO}]=(164.2 \pm 35.8)\left[\mathrm{C}_{2} \mathrm{H}_{2}\right]+(71.8 \pm 4.4) \mathrm{ppb}
$$

for the Northern Hemisphere and

$$
\left[\mathrm{CO} \mid=(664.2 \pm 49.6)\left[\mathrm{C}_{2} \mathrm{H}_{2}\right]+(42.5 \pm 4.2) \mathrm{ppb}\right.
$$

for the Southern Hemisphere.

However, due to calibration problems the absolute value for the slope and the axis intercept may be wrong by a factor of two. The background $\mathrm{CO}$ mixing ratio of $72 \mathrm{ppb}$ in the Northern Hemisphere is about twice the CO-background of about $35 \mathrm{ppb}$, which arises from calculations for the case of photostationary state conditions for $\mathrm{CO}$ with the oxidation of $\mathrm{CH}_{4}$ as the sole source of $\mathrm{CO}$ and the reaction with $\mathrm{OH}$ as the sole sink (Seiler et al., 1984; Warneck, 1988). The $\mathrm{CO} / \mathrm{C}_{2} \mathrm{H}_{2}$ ratio agrees fairly well with the ratios we can expect from the dominant sources in the 
Northern Hemisphere and the Southern Hemisphere, respectively. In the Northern Hemisphere the dominant source for $\mathrm{CO}$ and $\mathrm{C}_{2} \mathrm{H}_{2}$ is fossil fuel combustion, in the Southern Hemisphere biomass burning. From the $\mathrm{C}_{2} \mathrm{H}_{2}$ emission estimates (Ehhalt and Rudolph, 1984) and the CO source estimates (Logan et al., 1981) we can calculate a global average $\mathrm{CO} / \mathrm{C}_{2} \mathrm{H}_{2}$ ratio of about 300 for the fuel combustion and about 1100 for biomass burning.

\subsection{The Contribution of Oceanic Emissions to the Atmospheric NMHC Levels}

In order to determine the contribution of oceanic emissions we use a simple onedimensional model which uses the ocean as the sole NMHC source. We adopted the fluxes calculated by Plass et al. (1992) from NMHC measurements in the ocean surface water during the same ship cruise. The fluxes were calculated using the model of Liss and Merlivat (1986). Between sea level and $12 \mathrm{~km}$ altitude the troposphere is divided into 20 levels, 10 of which cover the planetary boundary layer. The lowest levels have a thickness of $25 \mathrm{~m}$, the uppermost $1000 \mathrm{~m}$. The atmospheric removal is driven by the reaction with the $\mathrm{OH}$ radical, in the case of the alkenes also by the reaction with $\mathrm{O}_{3}$. The rate coefficients were taken from Atkinson (1986) and Atkinson et al. (1989), respectively. Temperature and pressure profiles were taken from the US Standard Atmosphere (1966). The model uses a prescribed $\mathrm{OH}$ profile and diurnal cycle. For the surface level the $\mathrm{OH}$ concentration was calculated with a simple algorithm using the following input parameters: pressure; temperature; relative humidity; photolysis frequencies of $\mathrm{O}_{3}, \mathrm{NO}_{2}$ and $\mathrm{HCHO}$; concentrations of $\mathrm{O}_{3}, \mathrm{CO}, \mathrm{HCHO}$ and the concentrations of $\mathrm{NO}_{2}$ assuming photostationary state conditions ( $T$. Brauers, private communication). The necessary parameters have been measured during the cruise (meteorological data, photolysis frequencies and $\mathrm{O}_{3}$ concentrations: cf. Platt et al., 1992; $\mathrm{NO}_{2}$ concentrations: cf. Rohrer and Brüning, 1992; HCHO concentrations: cf. Harris et al., 1992). For this calculation the $\mathrm{CO}$ concentrations from grab samples have been used since for these measurements the calibration is assumed to be better than for the in-situ measurements. The uncertainty of the emission rates is assumed to be less than a factor of 2 (Plass et al., 1992). The shape of the vertical OH profile was adopted from Chameides and Cicerone (1978). For the diurnal cycle of $\mathrm{OH}$ a sinoid curve was used. The shape of the vertical $\mathrm{OH}$ distribution and diurnal cycle are shown in Figure 4(a) and (b) together with the profile of the eddy diffusion coefficient (Fishman and Carney, 1984), (Figure 4(c)). Our model does not include convective cloud transport and, thus, is not adequate for the ITCZ. The average $\mathrm{O}_{3}$ mixing ratios and profiles were taken from Smit et al. (1990) (Figure 4(d)). The time steps for integration were between 10 and $100 \mathrm{sec}$; the calculation ended when the diurnal cycles of consecutive days showed a relative change of less than $10^{-4}$.

In Figures 5(a) and (b) the hemispheric averages of the calculated mixing ratios in the lowest level $(0-25 \mathrm{~m})$ are compared with the hemispheric averages of the 

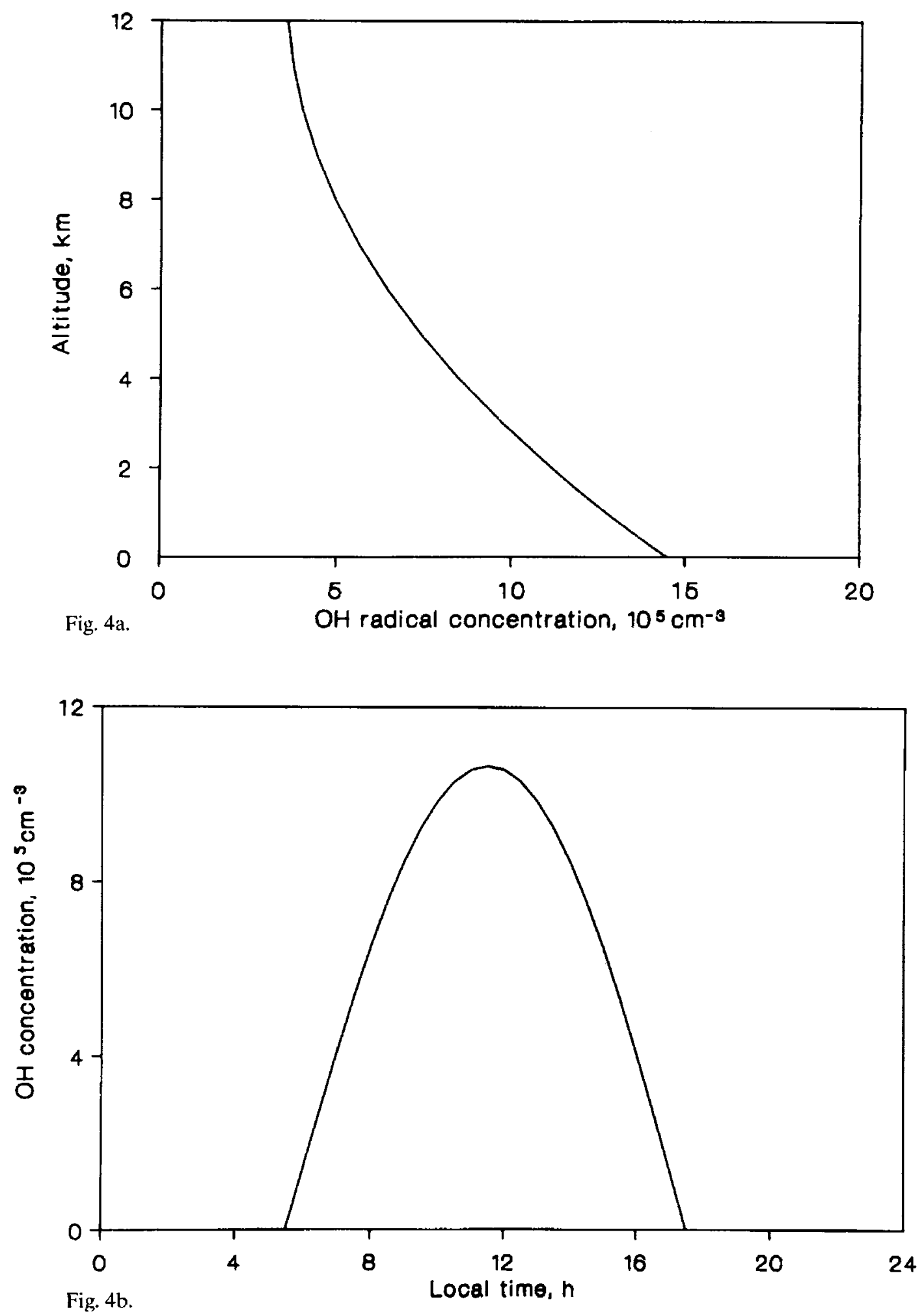

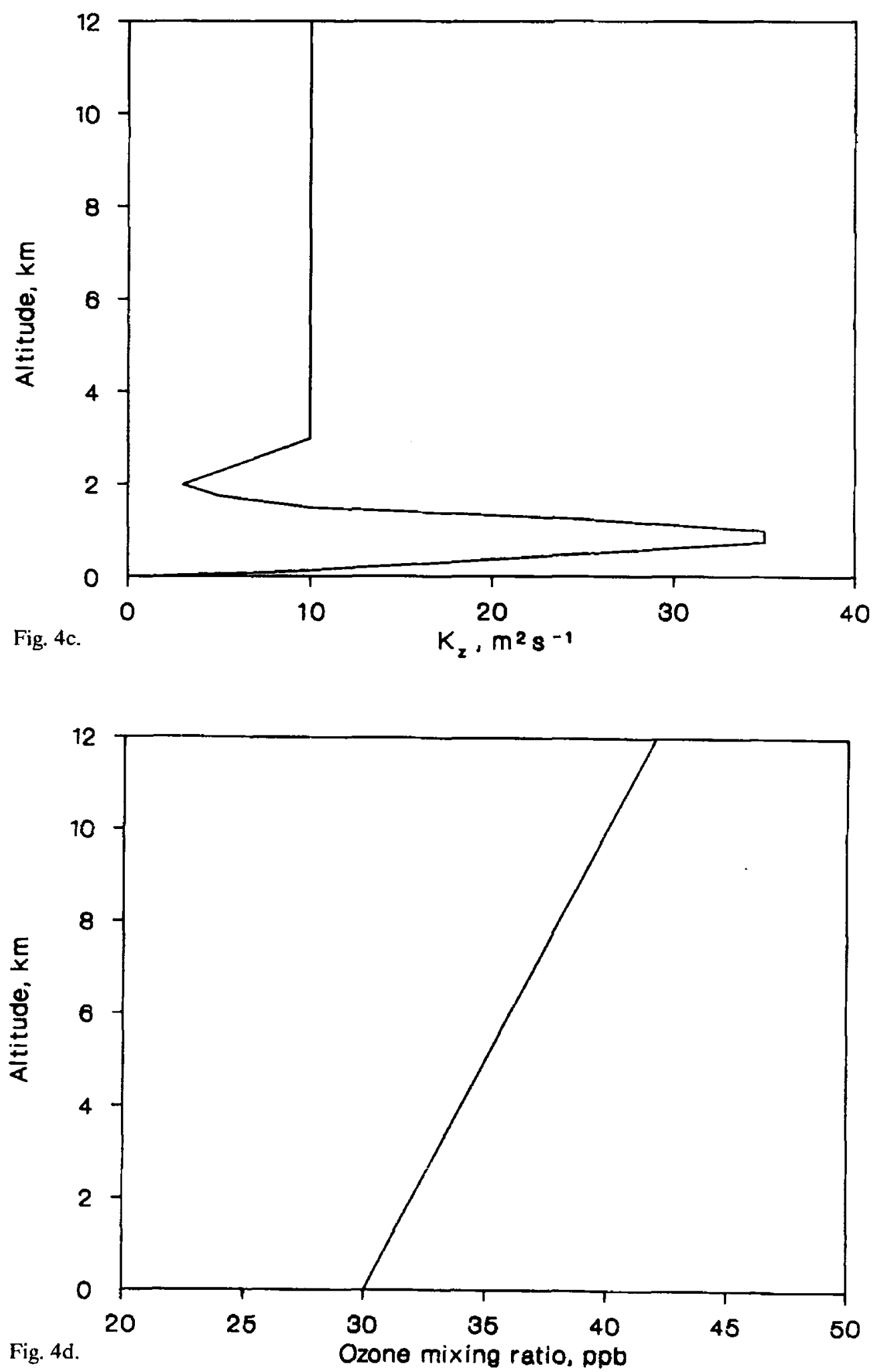

Fig. 4. Input parameters for the eddy diffusional model. (a) vertical distribution of $\mathrm{OH}$ concentration, (b) diurnal cycle of $\mathrm{OH}$, (c) vertical profile of the eddy diffusion coefficient, (d) vertical distribution of $\mathrm{O}_{3}$. 

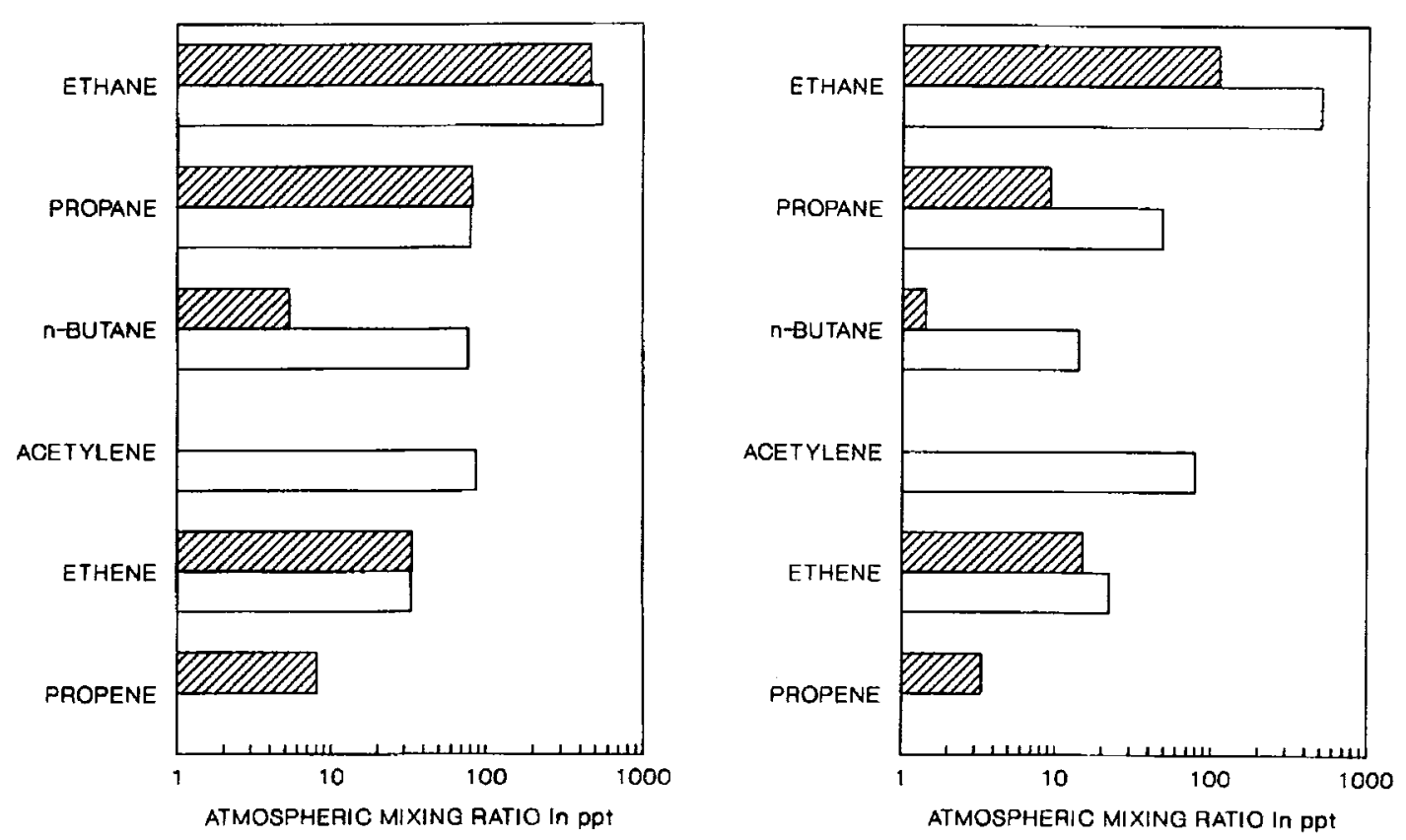

Fig. 5. Comparison of the calculated mixing ratios (hatched bars) and measured mixing ratios (open bars), logarithmic scales. The calculated acetylene emissions were below I ppt. (a) ITCZ to $35^{\circ} \mathrm{N}$, (b) equator to $30^{\circ} \mathrm{S}$.

measured mixing ratios (ITCZ to $35^{\circ} \mathrm{N}$ for the Northern Hemisphere, equator to $30^{\circ} \mathrm{S}$ for the Southern Hemisphere). The oceanic emissions of shortlived alkanes like $n$-butane can account for only less than $10 \%$ of the atmospheric mixing ratios, a consequence of the rather low oceanic emissions. The agreement between calculated and measured ethene mixing ratios is very good. On the average the atmospheric removal seems to be well balanced by oceanic emissions.

The results for the Southern Hemisphere reflect the lower oceanic emission rates in the southern Atlantic (Plass et al., 1992). For ethane and propane oceanic emissions account for about $20 \%$, for $n$-butane for less than $10 \%$. The mainly continental origin of these compounds is still visible. Oceanic ethene emission contributes about $70 \%$ to the atmospheric concentration. Since the oceanic acetylene source is negligible, there is no significant contribution of this source to the tropospheric levels.

Surprisingly enough, there seems to be a substantial contribution to the observed tropospheric ethane and propane levels by oceanic emissions. However, we have to consider that our simple model neglects possible changes of the model parameters with season, especially of the NMHC sources and sinks. For compounds with atmospheric residence times which are comparable to the timescale of such changes, this may cause significant errors. We do not know the seasonal variability of the oceanic NMHC sources, but we can esitmate the seasonality of the main sink, namely the $\mathrm{OH}$ removal reaction. In order to get an idea about the magnitude of the possible effect of the seasonal variability of $\mathrm{OH}$, we ran our model 


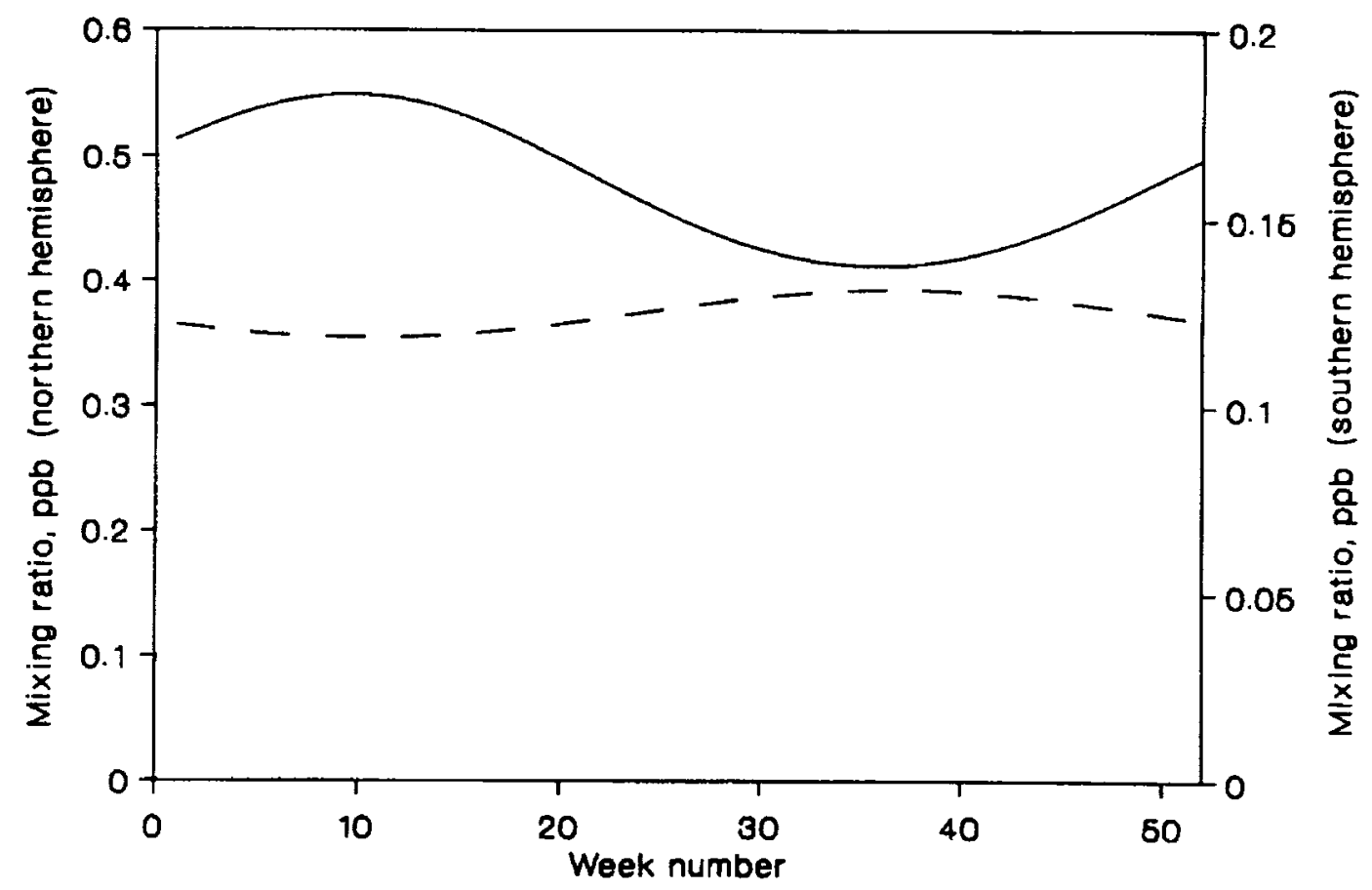

Fig. 6. Calculated seasonal cycles of ethane (see text) for the Northern Hemisphere (solid line) and Southern Hemisphere (dashed line).

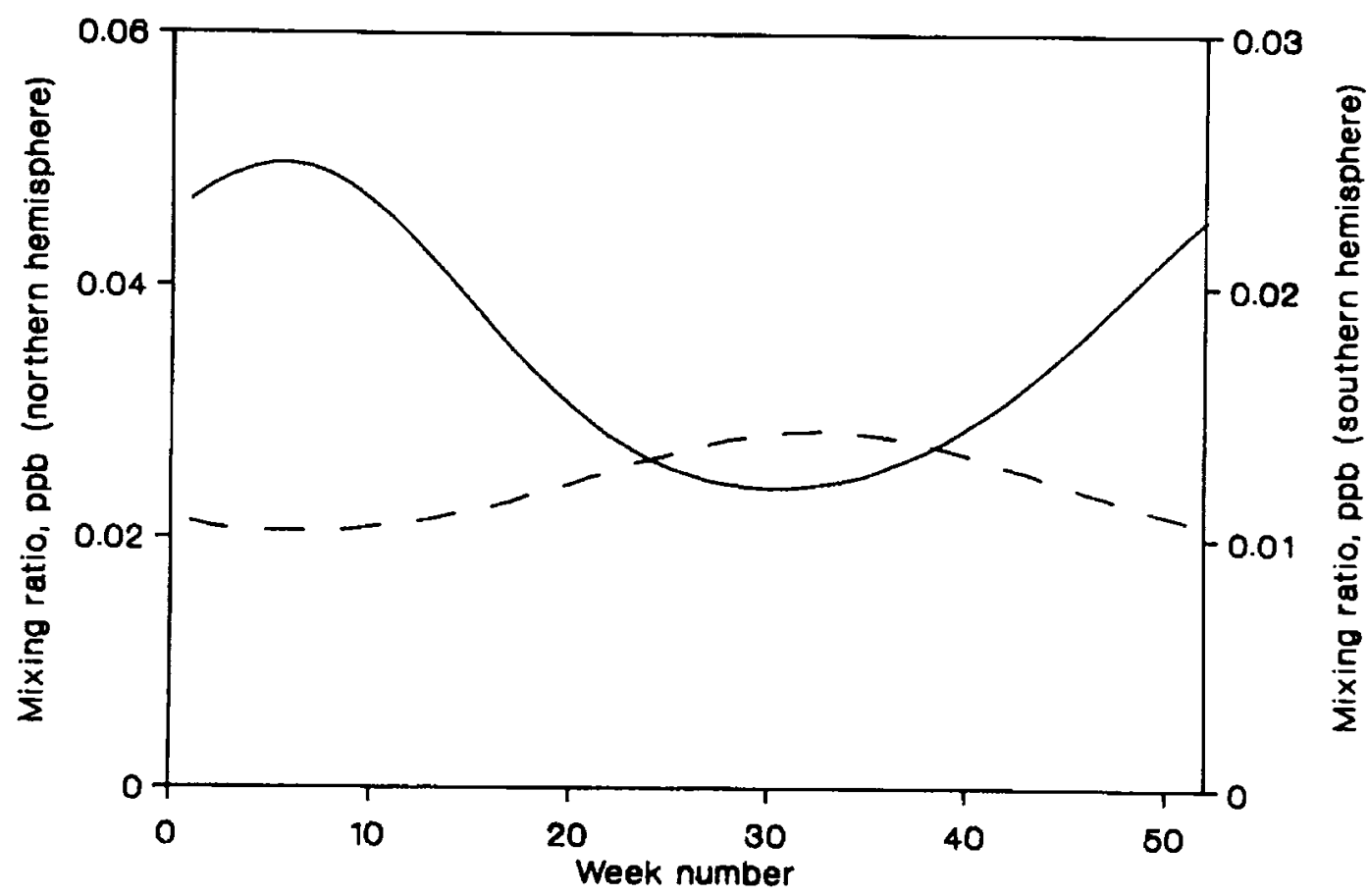

Fig. 7. Calculated seasonal cycles of propane (see text) for the Northern Hemisphere (solid line) and Southern Hemisphere (dashed line). 
through complete seasonal cycles. We used the seasonal change of the $\mathrm{OH}$ radical concentration given by Volz et al. (1981) for $30^{\circ}$ latitude but scaled it to match our $\mathrm{OH}$ estimate for September/October in order to be compatible with our calculation including only the diurnal cycle. The results for ethane and propane are given in Figures 6 and 7, which show the seasonal cycles for both hemispheres resulting from these calculations. In the Northern Hemisphere, both ethane and propane mixing ratios in September/October are considerably lower and, in the Southern Hemisphere, only slightly higher than calculated for steady-state conditions. These results seems to be more appropriate for discussing the contribution of oceanic emissions of these compounds to their atmospheric levels. In the Northern Hemisphere oceanic emission of ethane and propane accounts for about $70 \%$ of the atmospheric level, in the Southern Hemisphere for $20-25 \%$.

The measured ethene mixing ratios agree on average with those calculated for steady state with oceanic emissions. They do not explain the observed structures in the atmospheric ethene distributions. To simplify the calculations, we used a box model which only represents the marine boundary layer in order to evaluate the atmospheric ethene budget as a function of latitude. From the one-dimensional calculations it can be concluded that the error in the atmospheric ethene removal is small if a boundary layer of $2 \mathrm{~km}$ altitude is considered (Smit et al., 1990). For the atmospheric removal of ethene, only the reaction with $\mathrm{OH}$ was considered. The removal by the reaction with ozone was neglected here as it contributes with less than $20 \%$ to the total ethene destruction. Thus, the atmospheric ethene removal can simply be calculated from the estimated $\mathrm{OH}$ radical concentration (see above) and the measured atmospheric ethene concentration extrapolated over the boundary layer. The error of the calculated ethene removal in the atmosphere is the sum of a number of individual errors. The reproducibility of the atmospheric ethene measurements is about $10 \%$, the variation of the height of the planetary boundary layer was about $30 \%$. The calculation of the $\mathrm{OH}$ concentration has an uncertainty of a factor of up to 2. The total error is increased by the fact that for both $\mathrm{OH}$ and $\mathrm{C}_{2} \mathrm{H}_{4}$ no gradient in the PBL was considered. Therefore both concentrations may be overestimated by $30 \%$. Thus, the total uncertainty of the atmospheric removal rate for ethene may occasionally be as high as a factor of 2 .

Figures 8 gives both the oceanic emission (Plass et al., 1992) and atmospheric destruction of ethene as a function of latitude. This plot shows that for a large latitude range, the oceanic emissions balanced the atmospheric destruction within the error limits. However, there are three latitude bands where the atmospheric removal considerably exceeded the oceanic emissions. In the latitude range between $15^{\circ} \mathrm{N}$ and the ITCZ, this is explained as mentioned above by the advection of airmasses from the African continent (see Figure 2). This results in increased ethene concentrations and, consequently, in higher atmospheric removal rates. The somewhat smaller but still significant deviations around the equator and at $20^{\circ} \mathrm{S}$ are not yet understood. In general, the oceanic ethene emissions in the Southern Hemisphere were considerably lower than in the Northern Hemisphere. 


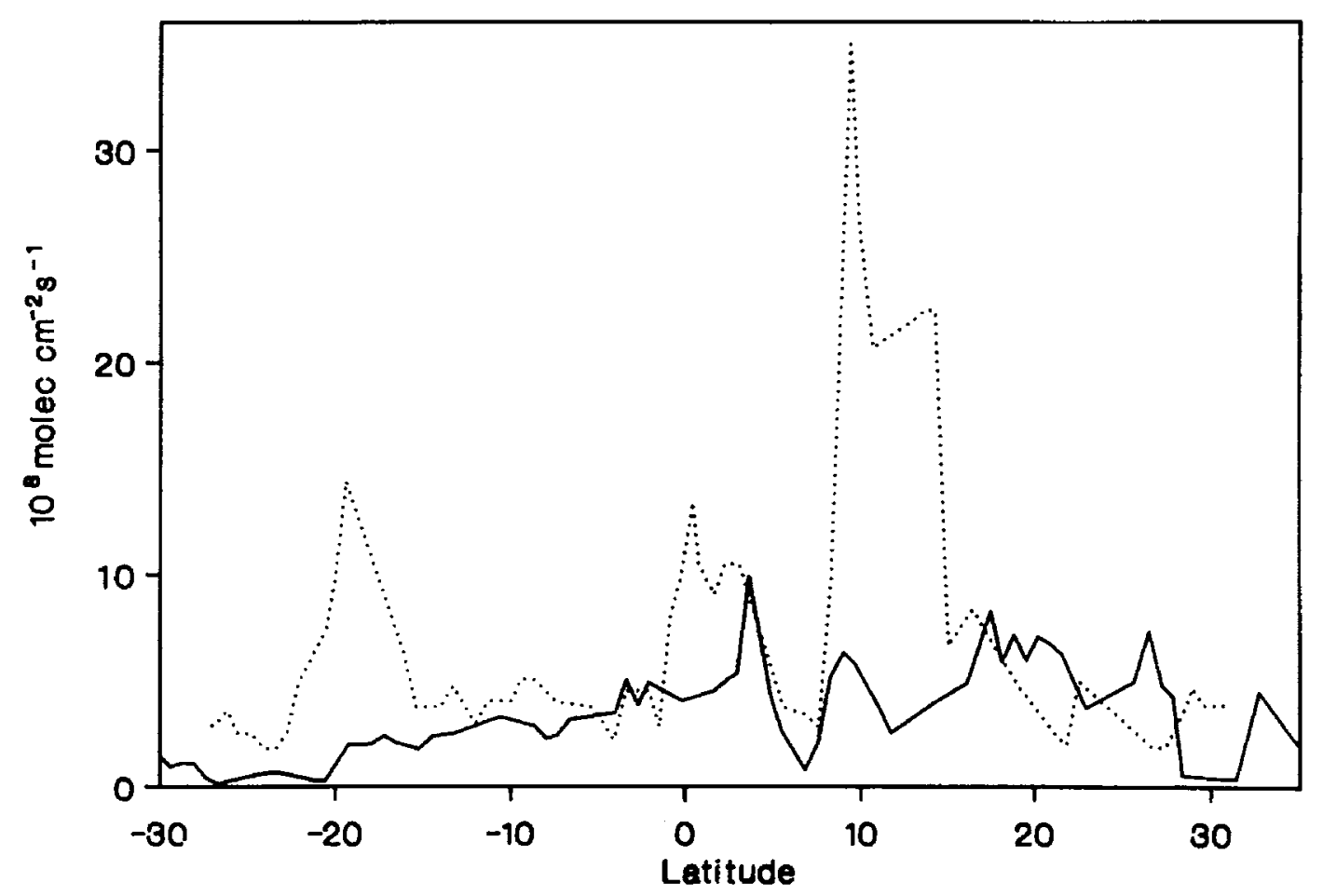

Fig. 8. Oceanic emission (solid line) and calculated atmospheric removal (dotted line) of ethene as a function of latitude, emission data after Plass et al. (1992).

This indicates that the difference in the average ethene mixing ratios of a factor of 2 between the Northern and Southern Hemispheres is primarily due to the difference in the oceanic emission rates.

\section{Conclusions}

The latitudinal distributions of several NMHC measured during September/October 1988 showed a number of structures, which could be assigned to four different conditions. North of $35^{\circ} \mathrm{N}$ the measured NMHC patterns indicated continentally influenced airmasses. Between $35^{\circ} \mathrm{N}$ and about $20^{\circ} \mathrm{N}$ all $\mathrm{NMHC}$ showed very low mixing ratios and the typical pattern of aged airmasses. Analysis of the weather maps indicated that the airmasses had no contact with the continents for several days. North of the ITCZ, the pattern of the different NMHC changed accompanied by an considerable increase of all NMHC. Backward trajectories showed a recent contract of the airmasses with the African continent. South of the equator, the NMHC patterns changed again and tracers of biomass burning such as acetylene, $\mathrm{CO}$, and ethane increased over a latitude range of about $10^{\circ}$ followed by a decrease towards increasing southern latitudes. This region of enhanced long-lived NMHC coincides in season and location with the area of elevated tropospheric ozone observed by Fishman et al. (1990). Since the pattern of the NMHC and other trace 
gases indicate aged biomass burning emissions, this supports the assumption that this area of increased tropospheric ozone is due to biomass burning.

The observed latitudinal distributions of light NMHC over the Atlantic also indicate that the observed compounds (with the exception of acetylene) are at least partly emitted by oceanic sources. Budget calculations show that the measured atmospheric ethene mixing ratios can be explained by oceanic emissions, since the removal of ethene is, in general, balanced by oceanic emissions.

While the contribution of oceanic emissions for ethane and propane seems to be more than $20 \%$, for $n$-butane oceanic emissions can only account for less than $10 \%$ of the atmospheric concentrations. Oceanic sources are negligible for acetylene. For ethane it is noteworthy that there is a significant hemispheric difference in the oceanic emission rates. However, our results indicate that there is a large contribution of biomass burning emissions, especially in the Southern Hemisphere. The seasonal cycle of this source seems to a large extent contribute to the change in the ethane level with season over the Atlantic.

The acetylene distribution is completely determined by long-range transport from continents. Comparison of the long-lived species like ethane and acetylene with a previous measurement series at a different season (cf. Rudolph and Johnen, 1990), gives evidence for seasonal variations in both hemispheres at practically all latitudes with minima in the respective late summer and maxima in late winter.

Although for the long-lived species some systematic trends are noticeable, our knowledge of the distributions of short-lived species with considerable oceanic sources and their possible seasonal variability is still incomplete. From our results, it seems justified to conclude that the concentrations of the reactive alkenes are primarily due to oceanic emissions and only occasionally due to long-range transport episodes.

\section{References}

Atkinson, R. A., 1986, Kinetics and mechanisms of the gas-phase reactions of the hydroxyl radical with organic compounds under atmospheric conditions, Chem. Rev. 85, 69-201.

Atkinson, R. A., Baulch, D. L., Cox, R. A., Hampson, R. F., Kerr, J. A., and Troe, J., 1989, Evaluated 
kinetic and photochemical data for atmospheric chemistry Supplement III, J. Phys. Chem. Ref. Data 18, No. 2, 881-1095.

Bonsang, B. and Lambert, G., 1985, Nonmethane hydrocarbons in an oceanic atmosphere, J. Atmos. Chem. 2, 257 -271.

Bonsang B., Kanakidou, M., Lambert, G., and Monfray, $P_{.,}$1988, The marine sources of $C_{2}-C_{5}$ aliphatic hydrocarbons, J. Atmos. Chem. 6, 3-20.

Blake, D. R. and Rowland, F. S., 1986, Global atmospheric concentrations and source strength of ethane, Nature 321, 231-233.

Chameides, W. L. and Cicerone, R. J., 1978, Effects of nonmethane hydrocarbons in the atmosphere, J. Geophys. Res. 83, 947-952.

Donahue, N. M. and Prinn, R. G., 1990, Non-methane hydrocarbon chemistry in the remote marine boundary layer, submitted to J. Geophys. Res.

Ehhalt, D. H., Rudolph, J., Meixner, F. X., and Schmidt, U., 1985, Measurements of selected $\mathrm{C}_{2}-\mathrm{C}_{5}$ hydrocarbons in the background troposphere: Vertical and latitudinal variations, J. Atmos. Chem. $3,29-52$.

Ehhalt, D. H. and Rudolph, J., 1984, On the importance of light hydrocarbons in multiphase atmospheric systems, Ber. Kernforschungsanlage Jülich, JÜL-1942, 1-43.

Fishman, J. and Carney, T. A., 1984, A one-dimensional photochemical model of the troposphere with planetary boundary layer parameterization, J. Atmos. Chem. 1, 351-376.

Fishman, J., Watson, C. E., Larson, J. L., and Logan, J. A., 1990, Distribution of tropospheric ozone determined from satellite data, J. Geophys. Res. 95, D4, 3599-3617.

Greenberg, J. P. and Zimmermann, P. R., 1984, Nonmethane hydrocarbons in remote tropical, continental and marine atmospheres, J. Geophys. Res. 89, D3, 4767-4778.

Harris, G., Klemp, D., Zenker, T., Burrows, J. P., Mathieu, B., and Jacob, P., 1992, Tunable diode laser measurements of trace gas during the 1988 Polarstern cruise and intercomparisons with other methods, J. Atmos. Chem. 15, 315-326 (this issue).

Jones, B. M. R., 1988, The measurement of ambient hydrocarbon concentrations in the atmosphere at Harwell during the period April 1986 to March 1987, Report AERE R 13174, Harwell Laboratory, Oxfordshire.

Lamontagne R. A., Swinnerton, J. W., and Linnenbom, V. J., 1974, $\mathrm{C}_{1}-\mathrm{C}_{4}$ hydrocarbons in and above the north and south Pacific, Tellus 26, 71-77.

Liss, P. S. and Merlivat, L., 1986, Air-sea gas exchange rates: introduction and synthesis, in P. BuatMenard (ed.), The Role of Air-Sea Exchange in Geochemical Cycling, D. Reidel, Dordrecht, pp. 113-127.

Liu, S. C., McKeen, S., and Trainer, M., 1989, Impacts of biogenic nonmethane hydrocarbons on the tropospheric chemistry, in P. J. Crutzen, K. C. Gerard, and R. Zander (eds.), Our Changing Atmosphere, Proceedings of the 28th Liege Int. Astrophys. Colloq., Liege, Belgium, 1989, pp. 419-431.

Logan, J. A., Prather, M. J., Wofsy, S. F., and McElroy, M. B., 1981, Tropospheric chemistry: A global perspective, J. Geophys. Res. 86, C8, 7210-7254.

Plass, C., Koppmann, R., and Rudolph, J., 1992, Light hydrocarbons in the surface water of the midAtlantic, J. Atmos. Chem. 15, 235-251 (this issue).

Platt, U., Brauers, T., Harris, G., and Rudolph, J., 1992, Atmospheric measurements during Polarstern cruise ANT VII $/ 1,54^{\circ} \mathrm{N}$ to $32^{\circ} \mathrm{S}$ : an overview, J. Atmos. Chem. 15, 203-214 (this issue).

Rasmussen, R. A. and Khalil, M. A. K., 1982, Latitudinal distributions of trace gases in and above the boundary layer, Chemosphere 11, 227-235.

Robinson, E., Hydrocarbons in the atmosphere, 1978, Pageoph 116, 372-384.

Rohrer, F., and Brüning, D., 1992, Surface $\mathrm{NO}$ and $\mathrm{NO}_{2}$ mixing ratios measured between $30^{\circ} \mathrm{N}$ and $30^{\circ} \mathrm{S}$ in the Atlantic region, J. Atmos. Chem. 15, 253-267 (this issue).

Rudolph, J. and Ehhalt, D. H., 1981, Measurements of $\mathrm{C}_{2}-\mathrm{C}_{5}$ hydrocarbons over the North Atlantic, $J$. Geophys. Res. 86, 11,959-11,964.

Rudolph, J., 1988, Two-dimensional distribution of light hydrocarbons: Results from the STRATOZ III experiment, J. Geophys. Res. 93, 8367-8377.

Rudolph, J., Jebsen, C., Khedim, A., and Johnen, F. J., 1984, Measurements of the latitudinal distribution of light hydrocarbons and halocarbons over the Atlantic, in B. Versino and G. Angeletti (eds.), Proceedings of the 3rd European Symposium on Physico-Chemical Behaviour of Atmospheric Pollutants, D. Reidel, Hingham, Mass., pp. 492-501. 
Rudolph, J., Ehhalt, D. H., Khedim, A., and Jebsen, C., 1982, Latitudinal profiles of some $\mathrm{C}_{2}-\mathrm{C}_{5}$ hydrocarbons in the clean troposphere over the Atlantic, Paper presented at 2nd Symposium on Composition of the Nonurban Troposphere, Am. Meteorol. Soc., Boston, Mass.

Rudolph, J., Johnen, F. J., and Khedim, A., 1986, Problems connected with the analysis of halocarbons and hydrocarbons in the non-urban atmosphere, Internat. J. Environ. Anal. Chem. 27, 97-122.

Rudolph J. and Johnen, F. J., 1990, Measurements of light atmospheric hydrocarbons over the Atlantic in regions of low biological activity, J. Geophys. Res. 95, 20,583-20,591.

Rudolph, J., Khedim, A., and Wagenbach, D., 1989, The seasonal variation of light nonmethane hydrocarbons in the Antarctic troposphere, J. Geophys. Res. 94, 13,039-13,044.

Schmidt, U., Khedim, A., Johnen, F. J., Rudolph, J., and Ehhalt, D. H., 1982, Two-dimensional distribution of $\mathrm{CO}, \mathrm{CH}_{4}, \mathrm{~N}_{2} \mathrm{O}, \mathrm{CFCl}_{3}$ and $\mathrm{CF}_{2} \mathrm{Cl}_{2}$ in the remote troposphere over the Atlantic Ocean, Preprint Volume: 2nd Symp. on the Composition of the Nonurban Troposphere, Williamsburg, VA 1982, American Meteorological Society, Boston, Mass., 52-55.

Singh, H. B. and Salas, L. J., 1982, Measurements of selected light hydrocarbons over the Pacific Ocean: Latitudinal and seasonal variations, Geophys. Res. Lett. 9, 842-845.

Seiler, W. et al., 1984, The cycle of atmospheric CO, Tellus 26, 116-135.

Smit, H., Gilge, S., and Kley, D., 1990, The meridional distribution of ozone and water vapor over the Atlantic Ocean between $30^{\circ} \mathrm{S}$ and $52^{\circ} \mathrm{N}$ in September/October 1988, in G. Restelli, and G. Angeletti (eds.), Physico-Chemical Behaviour of Atmospheric Pollutants, Proceedings of the 5th European Symposium, Varese, 1989, Kluwer, Dordrecht, pp. 630-637.

U.S. Standard Atmosphere Supplements, 1966, U.S. Government Printing Office, Washington D.C.

Volz, A., Ehhalt, D. H., and Derwent, R. G., 1981, Seasonal and latitudinal variation of ${ }^{14} \mathrm{CO}$ and the tropospheric concentration of $\mathrm{OH}$ radicals, J. Geophys. Res. 86, 5163-5171.

Warneck, P., 1988, Chemistry of the Natural Atmosphere, International Geophysics Series Vol. 41, Academic Press, New York. 